that these cultivars do respond to photoperiod with some of the characteristics of short-day plants. These studies were designed to determine the effects of photoperiod and of 1 ight and temperature preceding and during the dark period on floral initiation in Pima cotton.

F1oral induction in Pima cotton, cultivars S-3 and S-4, occurred earlier (at lower node levels on the main stem) under short winter days than under long summer days when plants were grown under natural light and a controlled temperature program. The intensities of red and far red 1 ight in natural sunlight were measured to determine if there were daily or seasonal changes in spectral quality which might be related to variations in floral initiation. Red light predominated during the day but the balance shifted to a predominance of far red light between sunset and darkness. This relationship was not seasonal.

Extending the dark period for 1.5 hours before sunset accelerated floral induction if the temperature during this period was above $30 \mathrm{C}$, but either had no effect or retarded induction if the temperature was below $30 \mathrm{C}$.

Shortening or interrupting the natural dark period with low intensity lights of different spectral composition retarded induction. The intensity of blue light, but not red or far red light, appeared to be related to induction. The increase in the node number of the first fruiting branch was almost directly proportional to the time interval between sunset and the period of illumination.

Floral initiation was most sensitive to photoperiod and to high temperatures during sunset during the second week of development after germination.

$$
* * * * *
$$

\title{
MODIFICATION OF FLOWERING IN PIMA COTTON WITH
}

\section{ETHEPHON}

Leonard L.H. Pinkas

Cotton (Gossypium barbadense L.), cultivar Pima S-4, may set fruit too low on the plant for efficient mechanical harvesting when grown on soils of less than average productivity at altitudes over 2500 feet. If, under these low-fruiting conditions, the first formed (lowest) floral buds could be easily removed, fruit set would be forced higher on the plant, thereby facilitating mechanical picking. This research was initiated to determine if ethephon could cause abscission of floral buds present at the time of application without reducing yield. Results of preliminary greenhouse experiments to test the effectiveness of the material and application methods are presented here.

Spray app1ications of $0.032 \mathrm{M}$ ethephon at the rate of 40 gallons per acre raised the node level of the first flower about four nodes (Table 1).

The effectiveness of ethephon at different stages of growth was determined. Groups of plants treated with $0.032 \mathrm{M}$ ethephon either 7 , 14, or 21 days after the initial group was tested, flowered at a statistically similar node level (Table 2). 
These results indicate that ethephon can cause abscission of the first-formed floral buds of Pima $5-4$ cotton. The material can be easily applied as a foliar spray. The timing of the application does not appear to be unreasonably critical. Further tests in the field will be necessary to determine if yield is affected.

Table 1. Node numbers of lowest surviving floral bud and first flower on Pima S-4 cotton plants sprayed with ethephon. Whole plants sprayed when first three floral buds were visible. Data are averages of four replications, four plants per replication.

\begin{tabular}{lcc}
\hline $\begin{array}{c}\text { Concentration } \\
M\end{array}$ & $\begin{array}{c}\text { Node number } \\
\text { of first } \\
\text { flower* }\end{array}$ & $\begin{array}{c}\text { Number of nodes } \\
\text { delay due } \\
\text { to treatment }\end{array}$ \\
\hline 0 & 4.2 & \\
0.008 & 5.0 & 0.8 \\
0.032 & 8.6 & 4.4 \\
\hline
\end{tabular}

*Within each test, a11 means are statistically different at the .05 level of probability.

Table 2. Node numbers of first flower on Pima S-4 cotton plants sprayed with single applications of ethephon at various times. Data are averages of three replications, four plants per replication.

\begin{tabular}{cccc}
\hline $\begin{array}{c}\text { Time of } \\
\text { application }\end{array}$ & $\begin{array}{c}\text { Concentration } \\
\mathrm{M}\end{array}$ & $\begin{array}{c}\text { Node number of } \\
\text { first flower* }\end{array}$ & $\begin{array}{c}\text { Number of nodes } \\
\text { delay due } \\
\text { to treatment }\end{array}$ \\
\hline $\begin{array}{c}\text { Unfolding of leaf } \\
\text { subtending first } \\
\text { floral bud }\end{array}$ & 0 & Test 5 & \\
& 0.008 & $8.5 \mathrm{~b}$ & 0 \\
7 days after first & 0.008 & $7.3 \mathrm{~b}$ & 1.8 \\
application & 0.032 & $10.3 \mathrm{ab}$ & 0 \\
14 days after first & 0.008 & $8.4 \mathrm{~b}$ & 3.7 \\
application & 0.032 & $12.2 \mathrm{a}$ & .1 \\
21 days after first & 0.008 & $8.9 \mathrm{ab}$ & 3.4 \\
application & 0.032 & $11.9 \mathrm{a}$ & 0 \\
\hline
\end{tabular}

*Within each test, means followed by a common letter are not statistically different at the .05 level of probability. 